Gut, 1984, 25, 1352-1357

\title{
Different patterns of intestinal transit time and anorectal motility in painful and painless chronic constipation
}

\author{
G A LANFRANCHI, G BAZZOCCHI, C BRIGNOLA, M CAMPIERI, AND G. LABÒ \\ From the Istituto di Clinica Medica e Gastroenterologia dell'Università di Bologna, Bologna, Italy
}

SUMMARY Anorectal motility and gastrointestinal transit time were studied in 25 patients complaining of non-organic constipation. Colonic pain was reported by 14 patients, it was absent in the remaining 11 . The group with painful constipation was composed of four men and 10 women and age onset of the symptom was $22 \cdot 1 \pm 5 \cdot 1$ years. The other group was composed only of women and painless constipation was reported to have begun at $7 \cdot 9 \pm 2 \cdot 2$ years previously. In the group presenting painful constipation higher values of the anal maximum resting pressure, of the amplitude of the rectoanal inhibitory reflex, lower values of sensation threshold, need to evacuate, maximum tolerable volume were recorded, in comparison with those registered in the painless constipation group. All these differences were significant. In the latter group the total transit time was always very slow $(186 \cdot 0 \pm 4 \cdot 7 \mathrm{~h})$, while it was quite variable in the other group, so that the mean was in the normal range $(79 \cdot 0 \pm 10 \cdot 0 \mathrm{~h})$. The data show that two different patterns of motor abnormalities can be recognised in constipated patients. The presence of colonic pain can suggest the characteristics of the underlying motor abnormality.

Chronic functional constipation is caused by disorders of colonic or rectal motility. Attempts to characterise a common underlying motor abnormality have led to disappointing conclusions. The most recent investigations report either increased or reduced, and even normal, intraluminal pressure changes of the sigmoid colon ${ }^{12}$ and the same results are registered regarding the reactivity of the internal anal sphincter to rectal distension. ${ }^{3-7}$ These contrasting findings may be because of a poor definition of constipation and to the heterogeneity of the examined patients.

The purpose of this study is to look for a correlation among clinical pictures, gastrointestinal transit time, and rectal motility in a group of constipated patients. It was considered useful to distinguish two groups of constipated patients: one characterised by painful constipation, the other by simple constipation - that is, without abdominal pain. This distinction is generally accepted and reported by several other workers, ${ }^{8-10}$ but no definite pathophysiological interpretation has ever

Address for correspondence: Prof G A Lanfranchi, Istituto di Clinica Medica e Gastroenterologia. Policlinico S. Orsola, Via Massarenti no. 9, 40138 Bologna, Italy.

Received for publication 21 February 1984 been given to explain the different symptomatological patterns.

\section{Methods}

PATIENTS

Patients admitted to our clinic complaining of chronic severe constipation were asked to take part in our research. Twenty seven patients volunteered to undergo all the following examinations: doublecontrast barium enema, proctosigmoidoscopy, evaluation of intestinal transit time, and study of rectal motility. Selection criteria included patients complaining of chronic constipation for more than five years, without any other digestive or systemic disorders. At the end of the preliminary study, two patients were excluded, one because Hirschprung's disease was diagnosed and one because the scheduled examinations were not completed. The final study involved 25 patients.

Detailed information about the following was obtained: frequency of spontaneous discharges, age onset of constipation, laxative consumption, colonic pain, according to the criteria of Manning et al, ${ }^{11}$ abdominal distension, and feeling of incomplete evacuation after defaecation. Total and segmental colonic transit time were investigated according to 
the method of Arhan et al. ${ }^{12}$ Briefly, 20 radioopaque markers (sections of a $3 \mathrm{~mm}$ thick radioopaque polyethylene nasogastric Portex tube of od 5 $\mathrm{mm}$ ) were ingested and plain film of the abdomen was taken every 24 hours until at least $80 \%$ of the markers was excreted, or for a maximum of eight days. The markers were counted in three segments of the large bowel: right, left, and rectosigmoid area. The mean transit time of the markers in every segment of the large bowel was calculated according to the method reported by Arhan. ${ }^{12}$ Anorectal function was assessed by means of a constantly perfused $1.2 \mathrm{~mm}$ diameter double lumen tube with side openings of $2 \mathrm{~mm}$ od. A third independent tube was fastened to a rubber balloon $(3 \times 4 \mathrm{~cm})$ for rectal distension. The probe was connected to Beckman transducers (4-327C) and to a Beckman recorder ( $R$ 611 ) and then positioned in the rectal ampulla and in the upper anal canal. The maximum resting pressure was considered as the highest pressure in the anal canal at rest, recorded by the pull-through technique. The reported values are the mean of three recordings. Rectal distension stimuli were obtained by inflation of 5-10-20-50 ml air and so on for 10 seconds with an interval of one minute until pain sensation was elicited. The following parameters were evaluated: maximum resting pressure of the anal canal, relaxation amplitude of the internal anal sphincter in response to balloon distension (rectoanal inhibitory reflex), rectal distending volume for rectoanal inhibitory reflex threshold, sensation threshold (perception of the distending balloon), evacuation threshold (perception of need to evacuate), maximum tolerable volume (pain threshold). Treatments with high residue diet or laxatives were stopped at least 15 days before the experiment began.

Transit time data and manometric results were compared with those previously obtained in a control group of 15 subjects without any gastrointestinal disorder, and balanced for age and sex. The analysis of variance showed that these parameters were not different from those recorded in the patients group.

\section{Results}

On the basis of the presence of colonic pain, it was possible to distinguish two groups of patients: one including 14 subjects with painful constipation and the other including 11 subjects with painless constipation. In the painful constipation group only two patients reported spontaneous discharges every three to five days and an irregular use of laxatives or enemas; in the painless constipation group only one patient reported spontaneous discharge about every eight days. As for the remaining patients of both groups, evacuation was always induced by the regular use of laxatives and enemas. Feeling of incomplete evacuation after defaecation was reported by all the patients of the painful constipation group except one and abdominal distension by all of them except two, while in the painless constipation group these symptoms were reported less frequently, with a statistically significant difference (Fig 1).

\section{FEATURES OF THE GROUPS}

The painless constipation group was composed only of women: mean age $42 \cdot 1 \pm 6 \cdot 3$ years (range: $16-80$ years). The painful constipation group was composed of 10 women and four men: mean age $46.0 \pm 2.9$ years (range: $23-62$ years). The age onset of constipation is shown in Figure 2. Constipation appearing in the first 10 years of life in $81.8 \%$ of the patients belonging to the painless constipation group and only in $42.8 \%$ of those of the painful constipation group $\left(p<0.05, \chi^{2}\right.$ test with Yates' variation).

\section{INTESTINAL TRANSIT TIME}

In the control population the upper limit of the excretion of $80 \%$ of the radio-opaque markers was $96 \mathrm{~h}$ (Fig. 3). The mean total transit time recorded in

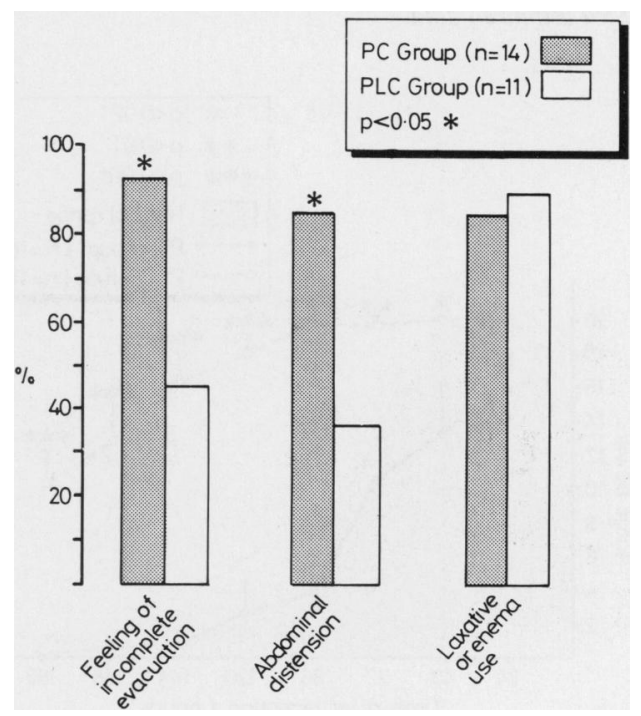

Fig. 1 Percentage of patients related to reported symptoms and to regular use of laxatives and enemas in groups with painful constipation (PC) and painless constipation (PLC). Difference between the two groups is significant with regard to 'feeling of incomplete evacuation' and 'abdominal distension' by $\chi^{2}$ with Yates' variation. 


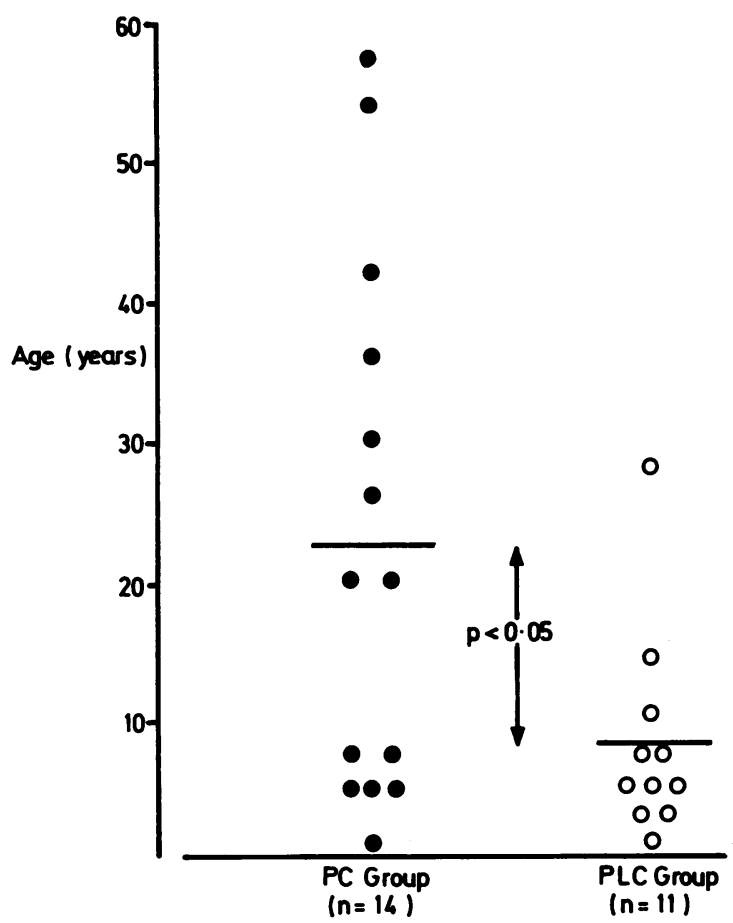

Fig. 2 Age onset of constipation in the groups with painful constipation (PC) and painless constipation (PLC).

Difference between the means is significant by Student's $\mathrm{t}$ test for unpaired data.

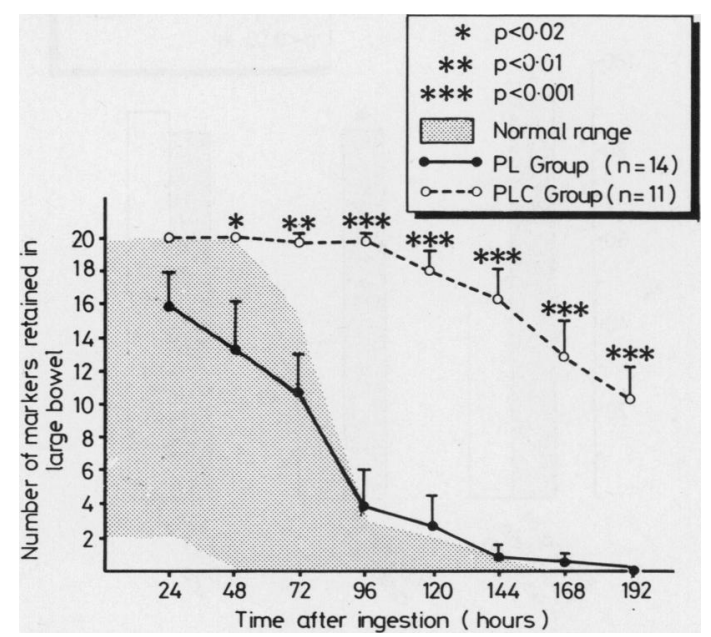

Fig. 3 Number of markers retained in large bowel in different days of the study. Normal range is represented by the shaded area. In groups with painful constipation (PC) and painless constipation (PLC) results are expressed as mean $\pm S E M$. Differences are always significant, except the first day (Student's t test for unpaired data). the painful constipation group was $79 \cdot 0+10 \cdot 0 \mathrm{~h}$ The analysis of the trend recorded for each patient showed that the total transit time was within the normal limit in 11 patients out of 14 : mean $63 \cdot 3 \pm 7 \cdot 5$ (range 20-88 h). The total transit time was higher than $96 \mathrm{~h}$ in the remaining three subjects: mean $140 \pm 2 \cdot 3$ (range 136-144 $\mathrm{h}$ ). In the painless constipation group the total transit time was always beyond the normal limit: mean $186 \cdot 0 \pm 4 \cdot 7$ (range 140-192 h).

The study of segmental colonic transit time showed that in all the three patients of the painful constipation group presenting slow total transit time the delay was recorded at the left colon level and in one of them also at the rectosigmoid area level. Furthermore, the markers were retained in the left colon for a longer number of hours than in controls in two patients with normal total transit time. In all these five patients the mean transit time in the left colon was $65 \cdot 7 \pm 8.0$, while the upper limit in controls was 39 hours. In the painless constipation group, segmental transit time was found to be delayed in 10 patients out of 11 at the left colon level (mean $83.7 \pm 9.6 \mathrm{~h}$ ), but also at the right colon level in six of them (mean $78.0 \pm 14.6 \mathrm{~h}$, versus an upper. normal limit of $38 \mathrm{~h}$ ) and/or at the rectosigmoid area level in four of them (mean $60 \cdot 6 \pm 15.6 \mathrm{~h}$, versus an upper normal limit of $35 \mathrm{~h}$ ). The transit was slow in all the three segments only in two cases, and in one case it was delayed in the rectosigmoid tract (105.6 h).

\section{RADIOLOGICAL AND SIGMOIDOSCOPICAL FINDINGS}

Barium enema did not show any organic lesion in all the patients who were examined: dolicocolon (defined as an elongated, tortuous colon) was registered in six cases $(42.8 \%)$ of the painful constipation group and in seven cases $(63.9 \%)$ of the painless constipation group. Megarectum (defined as a dilatation of the rectum and sigmoid tract rising out of the pelvis) was recorded in two patients of the painless constipation group.

Sigmoidoscopy showed only haemorroids, and even these seldom, with similar severity and frequency in the two groups $(20 \%$ in the painful constipation group and $32.4 \%$ in the painless constipation group).

\section{RECTAL MOTILITY STUDY}

The anal canal maximum resting pressures are shown in Figure 4. The mean of the painful constipation group was much higher than the normal range and the pressure was within normal limits in only two patients; the mean of the painless constipation group was within the normal range, 


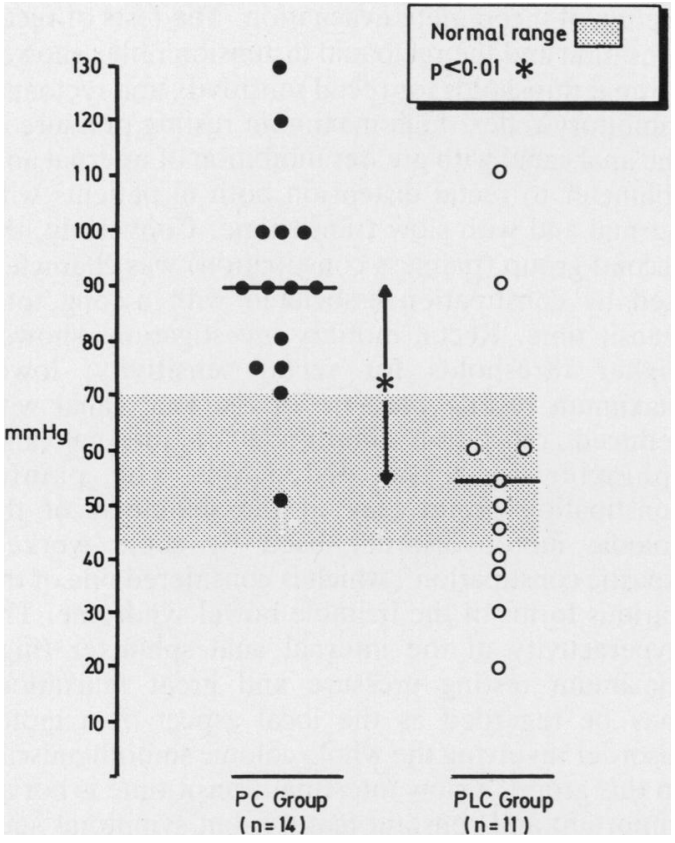

Fig. 4 Maximum resting pressure of anal canal in patients with painful constipation (PC) and with painless constipation (PLC). Difference between mean of the two groups is significant by Student's t test for unpaired data. Shaded area represents range of values recorded in normal group.

though a remarkable dispersion of the values was recorded.

The rectoanal inhibitory reflex amplitude at the progressive distending volumes was constantly greater in the painful constipation group than in the painless constipation group (Fig. 5) at each step of inflation. The means of the rectoanal inhibitory reflex amplitudes were, respectively, in the upper and lower areas of the normal range. A linear relation between the different rectoanal inhibitory reflex amplitudes and logarithm of rectal distending volumes was found in both groups. The rectoanal inhibitory reflex duration (Fig. 6) did not differ in the two groups and it was always within the normal range for all the volumes of rectal distension. A linear relation between the rectoanal inhibitory reflex duration and the distending volume logarithm was found. The rectal distending volume necessary to induce the rectoanal inhibitory reflex appearance was $12.8 \pm 1.4$ in the painful constipation group and $19.0 \pm 3.3 \mathrm{ml}$ air in the painless constipation group (Fig. 7).

The sensation threshold was reported at $26 \cdot 0 \pm 5 \cdot 5$ $\mathrm{ml}$ air inflated in the rectal balloon in the painful

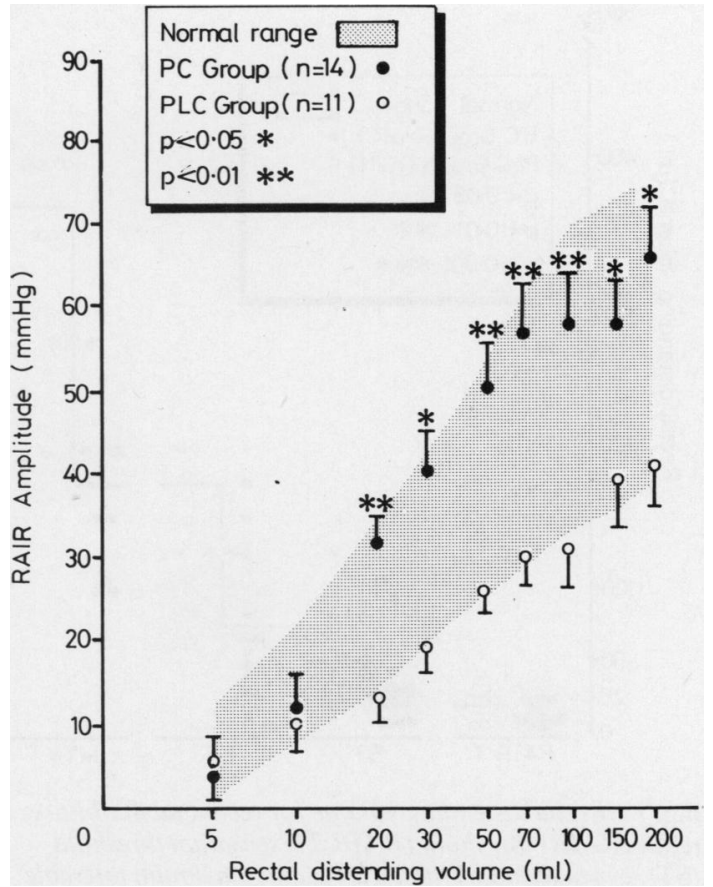

Fig. 5 Relation between rectoanal inhibitory reflex (RAIR) amplitude (mean $\pm S E M$ ) and logarithm of rectal distending volume in patients with painful constipation (PC) and painless constipation (PLC). Difference between amplitudes in two groups was significant only at $20 \mathrm{ml}$ and at subsequent volumes by Student's t test for unpaired data. Shaded area represents range of values of normal group.

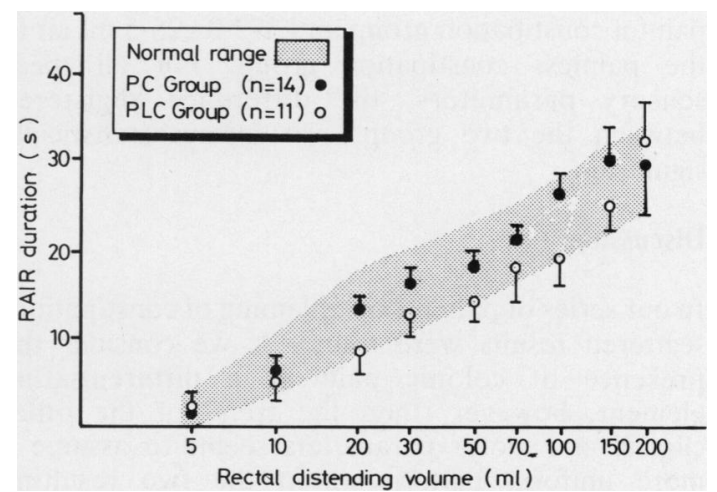

Fig. 6 Relation between rectoanal inhibitory reflex (RAIR) duration (mean $\pm S E M$ ) and logarithm of rectal distending volume in group with painful constipation $(P C)$ and in group with painless constipation (PLC). Shaded area represents the range of the control group's values. 


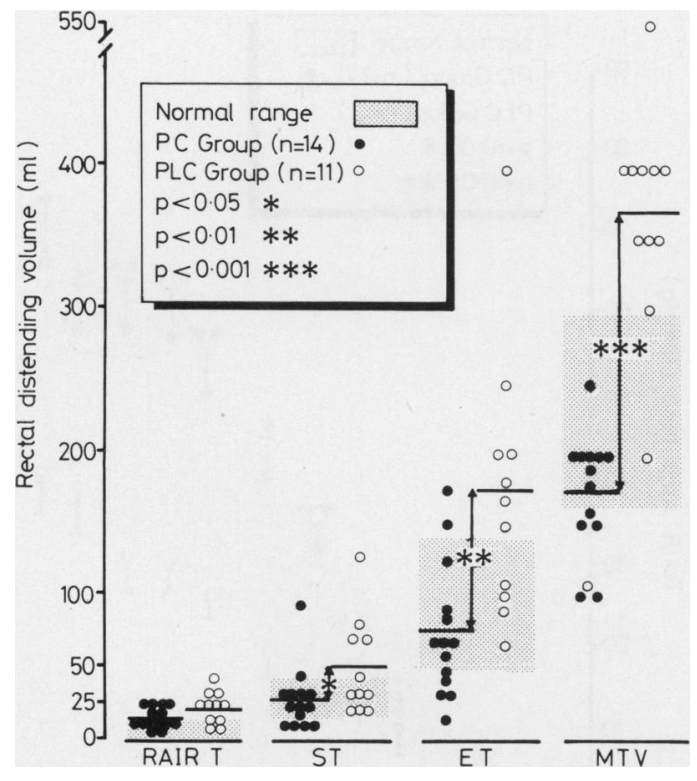

Fig. 7 Rectal distending volume for rectoanal inhibitory reflex (RAIR) threshold (RAIR T), sensation threshold $(S T)$, evacuation threshold (ET), and maximum tolerable volume (MTV) in patients with painful constipation (PC) and in patients with painless constipation (PLC). Shaded area represents range of control group's values. Statistical analysis was performed by Student's t test for unpaired data.

constipation group and at $49.0 \pm 10.4 \mathrm{ml}$ air in the painless constipation group. The evacuation threshold was reported at $75.0 \pm 12.4 \mathrm{ml}$ air in the painful constipation group and at $174.0 \pm 28.0 \mathrm{ml}$ air in the painless constipation group. The maximum tolerable volume was at $170.0 \pm 11.0 \mathrm{ml}$ air in the painful constipation group and $372.0 \pm 25.5 \mathrm{ml}$ air in the painless constipation group. For all these sensory parameters, the difference registered between the two groups was always statistically significant.

\section{Discussion}

In our series of patients complaining of constipation, scattered results were found. If we consider the presence of colonic pain as a differentiating element, however, then the trend of the other clinical and motor parameters seems to assume a more uniform pattern within the two resulting groups.

The first group (painful constipation) was characterised by constipation associated with a transit time at an upper limit of normal; most patients complained of abdominal distension and feeling of incomplete evacuation. The tests of rectal sensation and the rectoanal distension reflex showed normal thresholds for rectal sensitivity and rectoanal inhibitory reflex, high maximum resting pressure of the anal canal with greater inhibition of internal anal sphincter to rectal distension both in patients with normal and with slow transit time. Conversely, the second group (painless constipation) was characterised by constipation associated with a long total transit time. Rectal motility investigations showed higher thresholds for rectal sensitivity, lower maximum resting pressure of the anal canal with reduced relaxation amplitude of internal anal sphincter to rectal distension. The painful constipation group may fit the definition of the colonic motor disorder used by some workers 'spastic constipation', which is considered one of the various forms of the irritable bowel syndrome. The hyperactivity of the internal anal sphincter (high maximum resting pressure and great relaxation) may be regarded as the local aspect of a motor disorder involving the whole colonic smooth muscle. In this group, a slow intestinal transit time is not an important and constant feature, but symptoms such as pain and abdominal distension are related to a transient entrapment of gas and stools. The painless constipation group may fall within what is called 'atonic constipation', or 'idiopathic constipation', or 'colonic inertia', or 'simple constipation', and its pathogenesis may be because of a reduced motor activity caused, at least in part, by a defect of colonic wall sensitivity, which we found at the rectal ampulla level. This deficiency may be the only explanation of the reduced resting pressure of the anal canal and rectoanal inhibitory reflex amplitude, even if the possibility of a primary hypoactive sphincter cannot be excluded. The peculiar clinical feature is the lack of abdominal pain, even distension is rarely reported. The assumption that the internal anal sphincter pattern reflects a similar motor abnormality of the sigmoid colon seems to be confirmed in the recent observation reported by Preston and Lennard Jones ${ }^{13}$ who distinguish between constipation with normal and slow intestinal transit: a high motility index of the sigmoid colon was recorded in the first group, while a very low motility index was registered in the second one.

In both groups of patients the transit time of the markers from ingestion to the arrival at the large bowel was always within 24 hours - that is, within the normal range, which confirms that constipation is a problem related principally to the colon and that it does not involve the other segments of the gastrointestinal tract. As regards segmental transit time, the major role in delaying the progression of 
the markers seemed to be played by the left colon, both in the painful constipation group and in the painless constipation group. In the latter group the slackening may also be at level of other tracts of the large bowel. Dischezia was found only in one patient; so far, the relevance of 'outlet obstruction' in the pathogenesis of constipation ${ }^{3}$ is not confirmed.

The prevalence of women patients was remarkable in the painful constipation group and total in the painless constipation group. In the latter group constipation was generally reported from the first years of life. Therefore, an inherited sex linked alteration may be inferred. Dolicocolon and megarectum were found at radiological examination, in nine patients with painless constipation out of 11 .

In conclusion, our results suggest the existence of two different disorders with two different pathophysiologic mechanisms and stress the importance of total transit time evaluation in each patient complaining of constipation, particularly if painful. Finally, the evaluation of the internal anal sphincter behaviour may become one of the criteria for the positive diagnosis of functional chronic constipation.

This paper has been partly submitted as an abstract at the 9th International Symposium on Gastrointestinal Motility in Aix-en-Provence, France, September 1983, and accepted for oral presentation.

\section{References}

1 Meunier P, Rochas A, Lambert R. Motor activity of the sigmoid colon in chronic constipation: comparative study with normal subjects. Gut 1979; 20: 1095-1101.

2 Chowdury AR, Dinoso VP, Lorber SM. Characterisation of hyperactive segment at the rectosigmoid junction. Gastroenterology 1976; 71: 584-8.

3 Martelli H, Devroede G, Arhan P et al. Mechanism of idiopathic constipation: outlet obstruction. Gastroenterology 1978; 75: 623-31.

4 Meunier P, Marechal JM, Jaubert de Beaujeu M. Recto-anal pressures and rectal sensitivity studies in childhood chronic constipation. Gastroenterology 1979; 77: 330-6.

5 Orr WC, Robinson MG. Motor activity of the rectosigmoid in patients with chronic constipation. [Abstract] Gastroenterology 1981; 80: 1244.

6 Behar J, Biancani P. Rectal motility studies in patients with chronic functional constipation. [Abstract] Gastroenterology 1982; 82: 1015.

7 Marzio L, Lanfranchi GA. Trento L, Labò G. Anal manometry in constipated patients. Gastroenterology 1979; 76: 1080-1.

8 Bockus HL. Simple constipation. In: Bockus HL, ed. Gastroenterology. Vol. 2. Section IV. Philadelphia. London, Toronto: Saunders, 1976: 936-53.

9 Schuster MM. Megacolon in adults. In: Sleisinger MH, Fordtran JS, eds. Gastrointestinal disease. Philadelphia. London, Toronto: Saunders, 1978: 1812-24.

10 Thompson WG, Heaton KW. Functional bowel disorders in apparently healthy people. Gastroenterology 1980; 79: 283-8.

11 Manning AP, Thompson WG, Heaton KW, Morris AF. Towards positive diagnosis of the irritable bowel. Br Med J 1978; 2: 653-4.

12 Arhan P, Devroede G, Jehannin B, et al. Segmental colonic transit time. Dis Colon Rectum 1981; 24: 625-9.

13 Preston DM, Lennard Jones JE. Does failure of bisacodyl-induced colonic peristalsis indicate intrinsic nerve damage? [Abstract] Gut 1982; 23: A891. 